\title{
Los Símbolos "Naturalizados" de Los Tres Gauchos Orientales
}

El estudio de cómo los símbolos de la literatura universal se han naturalizado en la literatura latinoamericana es, tal vez, una de las apuestas críticas más interesantes que se pueden proponer al aproximarse a una corriente literaria como la gauchesca. El carácter distintivo nacional que ha hecho coherentes y unitarios a poemas de estructura y origen hispánico en países sin una tradición literaria muy intensa, como lo eran la Argentina y el Uruguay a mediados del siglo $\mathrm{xx}$, forma parte de un proceso de naturalización de símbolos de notas creativas muy particulares. Esta naturalización o "nacionalización", como gustara decir algún crítico, ha supuesto la incorporación vertebrada de una serie de motivos, preocupaciones y constantes temáticas a la literatura, pero sobre todo la creación de una lengua capaz de expresar con vitalidad esa intención estética.

En este sentido, pocos momentos de la historia literaria del Uruguay ofrece un conjunto de obras más directas, nacionalizadas y de clara significación política y social, como las correspondientes al período de auge de la poesía gauchesca. Esta literatura ha tenido en Los tres gauchos orientales de Antonio D. Lussich a una de sus obras más genuinas, representatividad que paga tributo a las coordenadas generales de la época y a lo que se convirtió luego en estereotipo y constante temática con pocas variantes imaginativas.

\section{Los GAUCHOS QUE DESAPARECEN}

En junio de 1872, un joven de veinticuatro años, sin antecedentes literarios conocidos, itrumpe en las letras rioplatenses con un exitoso alegato poético. Se llama Antonio Lussich y reclama del gobierno más

\footnotetext{
1 Antonio Dionisio Lussich nació en Montevideo el 23 de marzo de 1848. En 1870, cuando estalló la revolución encabezada por Timoteo Aparicio se alistó en sus filas, habiendo vivido y protagonizado en ese carácter varias batallas (Paso Severino, Corralito, el Sauce, Manantiales). Al firmarse la paz de abril
} 
consideración y mejores condiciones de tratamiento para el gaucho, a los que dice deber "las expansiones más intimas de sus veinte años". Lussich acaba de pasar dieciocho meses enrolado en el ejército revolucionario del Coronel Timoteo Aparicio y ha descubierto, apasionadamente, a lc largo de agitadas campañas militares, las injusticias, contradicciones y explotación de que era objeto el gaucho en la campaña oriental. $\mathrm{H}_{2}$ tenido una experiencia vital muy similar a la de Bartolomé Hidalgo, Estanislao del Campo, Hilario Ascasubi y el propio José Hernández ${ }^{2}$ y habrá de reaccionar de una forma muy parecida: publicando un largo poema gauchesco "haciendo únicamente justicia a esos desgraciados parias, víctimas del abandono en que viven, despojados de todas las garantías a que tienen derecho como ciudadanos de un pueblo libre".s

En ese mismo año de 1872, escribiría Ascasubi en el prólogo a la edición parisina de Paulino Lucero:" "Mi ideal y mi tipo favorito es el gaucho, más o menos como fue antes de perder mucho de su faz primitiva por el contacto con las ciudades.". Más fríamente, José Hernández también en 1872, manifiesta su preocupación por "copiar sus reflexiones", dibujar "el orden de sus impresiones y de sus defectos", en "retratar" las especialidades propias de "este tipo original de nuestras pampas, tan poco conocido por lo mismo que es difícil estudiarlo".

de 1872 es probable que Lussich ya tuviera redactadas muchas décimas de Los tres gauchos orientales que leyó a su amigo Aróztegui. Este lo estimuló a proseguir en esa dirección y Lussich "buscó un tema", encontrándolo en la propia revolución que habia protagonizado. El éxito de esta obra lo llevó a escribir El matrero Luciano Santos y Cantalicio Quirós y Miterio Campos en un baile del Club Uruguay en los años sucesivos. Sin embargo, después de 1883, Lussich se vuelca totalmente a otras actividades: con sus hermanos maneja una empresa de salvataje marítimo y, desde 1896 , transforma los arenales de Punta Ballena en la costa uruguaya en el tercer parque botánico del mundo. Con la primera recibió condecoraciones y premios, habiendo escrito varios documentos sobre naufragios célebres (ver bibliografía de Lussich al final), y con el segundo un adecuado retiro para sus últimos años. Allí, bajo los árboles que plantara y frente al mar, pidió ser enterrado al morit, cuando ya había cumplido ochenta años, el 5 de junio de 1928.

2 Todos estos poetas gauchescos han tenido una experiencia juvenil revolucionaria. Hidalgo, "el barbero", se había enrolado contra los ingleses, los españoles luego y, finalmente, contra los portugueses; Ascasubi, en un espectro aventurero más amplio, protagonizó batallas, espectaculares huidas y convivió con famosos matreros; Del Campo combate en Cepeda y Pavón; Hernández en San Gregorio, Tala y llega a ser Teniente del Regimiento del Coronel Sotelo.

3 En la carta que dirigiera a su editor Antonio Barreiro y Ramos en oportunidad de la cuarta edición de Los tres gauchos orientales en 1883 y que pidiera se insertara en el libro, Lussich enfatiza "la causa que defiendo, desprendido de partidismo exaltado". El gaucho es no sólo su tema, sino también su motivación y así confiesa que "me creería feliz si del conjunto hubiese, a lo menos, conseguido entresacar alguno de los rasgos más acentuados de la existencia agitada y seminómada del verdadero gaucho."

4 En París, en 1872, Ascasubi publicó sus obras completas "a instancias de mis amigos", según confięsa en el prólogo que las precede fechado el 2 de agosto de ese año. 
Sin embargo, el manifiesto propósito común a la literatura gauchesca de Ascasubi o Hernández, tiene en la obra de Antonio Lussich unas coordenadas de inmediatez y compromiso mucho mayores, porque justamente en el momento en que aparece publicado Los tres gauchos orientales, el Uruguay vive una gran politización a la que hace continua referencia su texto, y se van creando las condiciones que cuajarán en el período militarista que se abre en 1876 con la dictadura del Coronel Latorre.

El gaucho tradicional que fuera espontáneo soldado de la independencia, la Guerra Grande y las revueltas revolucionarias de los años que van de 1852 a 1872 , no tiene aparentemente lugar en la nueva sociedad emergente del Tratado de Paz del 6 de abril de 1872. La explotación ganadera se tecnifica, la propiedad rural se concentra y se alambran los campos terminando con un concepto de "estancia cimarrona" de la que fuera sinónimo el nomadismo y tradicional estilo de vida gauchesco, una perdida Arcadia que se va idealizando en forma abstracta y, muy probablemente, con bases poco reales.

La ruta abierta de los campos urugtrayos se cierra para los jinetes y los gobiernos de la época, preocupados por afianzar el ideal del estado unitario y centralizado, estimulan una fuerte represión contra los últimos "hombres sueltos" de la campaña oriental. Llegan a escasear los caballos y el gaucho, cuando no se convierte en peón de estancia, se ve obligado a refugiarse en los rancheríos marginales o a lanzarse a una difícil existencia "matreta".

Paradójicamente, la literatura canta y glorifica al gaucho cuando su figura ya es crepuscular y está esencialmente derrotado. No puede olvidarse que hasta ese momento, la literatura oficial y administrativa había sido muy tajante con estos "disolutos que no queriendo volver al buen camino, huyen y se refugian entre los infieles para vivir a su capricho." Reivindicaciones poéticas como la de Lussich llegan tarde para quienes, justa o injustamente, se aparecían como integrantes de "partidas de desertores que hacen cuantos males les sugiere su perversidad", saquean, "hacen burla de la justicia" y son llamados "baqueanos de ladrones, malévolos, vagabundos, gauchos". ${ }^{5}$

Los que iban de estancia en estancia "buscando juegos y camorras, sin respeto a la justicia" unos años antes, son ahora los "cantados"

5 Es interesante el estudio de la evolución del concepto "gaucho" en el Uruguay, desde la proscripta condición de la época de la colonia ( $L a$ vida cotidiana en la Colonia por Washington Lockhardt; Arca, Montevideo, 1967; e Historia de los pueblos orientales por Aníbal Barrios Pintos; Edic. Banda Oriental, Montevideo, 1971) hasta su glotificación literatia, evolución que analiza Fernando O Assunçao en El gaucho: su espacio y su tiempo' (Montevideo, 1969). 
héroes de las "patriadas" revolucionarias. Heroicos, pero vencidos. El propósito de entresacar algunos de los rasgos más acentuados de "la existencia - agitada y semi-nómade del verdadero gaucho", como anunciara en su prólogo, aparece continuamente ratificado en el texto de Los tres gauchos orientales. Ello le valió un gtan éxito editorial momentáneo: cuatro ediciones en once años con un total de dieciséis mil ejemplares. ${ }^{6}$ Pero esta misma condición de alegato circunstancial y el hecho de que el gaucho como prototipo tendía a desaparecer, llevó a que el poema fuera olvidado después de 1883, al punto de que Lussich en su madurez era conocido únicamente como regenteador de una empresa de salvataje marítimo, como autor de libros sobre naufragios célebres y como forestador de la zona costeña de Punta Ballena, espléndido bosque donde fuera enterrado al morir en $1928 .^{7}$

\section{I: LOS DATOS REALES Y SU FORMULACIÓN ESTÉTICA}

El estudio de Los tres gauchos orientales y la obra que lo siguiera en la edición de 1873, El matrero Luciano Santos, en base a todos estos antecedentes, obliga a dos operaciones analíticas constitutivas y concutrentes. Por un lado es necesario tener en cuenta la realidad histórica de los hechos natrados, los personajes como prototipos reales y las características de circunstancia que llevaron a un conjunto de elementos diversos a componer una unidad poemática. Al mismo tiempo, también es importante la realidad fijada en los poemas gauchescos precedentes y simultáneos, incluida la cutiosa y confundida relación con el autor de Martin Fierro, ${ }^{8}$ ya que la obra de Lussich se inscribe sin mayores distingos en un conjunto más general.

${ }^{6}$ Las ediciones de 1872 y 1873 fueron casi simultáneas y estuvieron marcadas por el éxito fulminante de la obra. Las ediciones posteriores son de 1877 y 1883. Para más detalle consultar al final Bibliografía de Lussich.

$7 \mathrm{La}$ importancia de su obra como forestador y su popularidad en el Uruguay eclipsaron su obra literaria, hasta que en 1945, merced a la tarea divulgadora de Jorge Luis Borges empezó una lenta revalorización del poeta Lussich que ha culminado en 1972 con festejos y reediciones de Los tres ganchos orientales en oportunidad del centenario de su primera edición.

8 En oportunidad de la revalorización de Lussich por parte de Borges se tendió a considerar al poema uruguayo como predecesor e influyente sobre el Martín Fierro de Hernández, contribuyendo para ello la amistad existente entre ambos escritores. Sin embargo, parte de ese equívoco partía de que Borges había utilizado la segunda edición de Los tres gauchos orientales donde Lussich ya había efectuado correcciones a la versión original de la primera edición. Disipa este malentendido con precisión, Eneida Sansone en el estudio que precede a la edición de los Clásicos Uruguayos en 1964, donde coteja las dos versiones de Los tres gauchos orientales con los versos de Hernández sobre los cuales presuntamente habría influido. 
Esta primera operación analítica - a la que llamamos "los datos reales y su formulación estética" - tiene por objeto la identificación de los elementos que integran el contexto total del poema y su representatividad "externa", todo lo que informa pero no constituye su unidad compleja. En esta primera fase juega un papel importante el lenguaje, sobre cuya particular significación deben distinguirse, a su vez, dos aspectos, siguiendo en este punto algunas de las sugerencias metodológicas de Juan Ferraté. 9

Hay que distinguir -en primer lugar - lo que hay de colectivo y la tonalidad social que es propia de Los tres gauchos orientales, lo que no puede limitarse al nivel estilístico en que se coloca el poeta o a la modalidad que adopta de acuerdo con las tradiciones literarias de la poesía gauchesca. Ello debe abarcar las convenciones de naturaleza extraliteraria que acepta y que son propias del habla de los gauchos que imita: al posible concepto de nivel estilístico literario de la expresión corresponde el concepto correlativo de la expresión lingüística real del grupo social "gaucho" elegido como tema, protagonista y "hablante".

En segundo lugar, es también importante lo que hay implícito en el poema, todo aquello que es tácito o circunstancial, pero lo que expreso evoca por asociación constituida mediante la experiencia conocida de la época. Gracias a ello es posible identificar por un lado la situación y la correspondiente actitud "real", así como la relación de "interlocutores" formalizada por los tres gauchós dialogantes, José Centurión, Julián Giménez y Mauricio Baliente.

\section{LA REPRESENTATIVIDAD EXTERNA DEL POEMA}

En sus 2376 versos el poema de Los tres gauchos orientales plantea cuál debe ser la posición correcta que deben adoptar los revolucionarios "blancos" después del Tratado de Paz de 1872. Las opiniones varían y son expresadas en un circunstancial diálogo por tres gauchos reunidos alrededor de un fogón donde hay "un puchero y el churrasquito ensartao". Se han dejado descansar los caballos, se han efectuado los saludos de rigor y se han extendido las invitaciones para tomar mate y algún trago de ginebra. Un pretexto de escenificación casi teatral y repetida en

9 "La operación de leer: principios y ejemplos de interpretación" contenido en Dinámica de la poesía (Seix Barral, Barcelona, 1968; pp. 175) constituye en la obra crítica de Juan Ferraté una completa metodología para la lectura de la poesía que creermos parcialmente aplicable a estas páginas, aunque parezca necesario también recordar los Selected Essays (Random House) de Robert Penn Warren y lós más genéricos conceptos de W. Stacy Johnson en Introduction to liferary cristicism (Heath, Boston, 1967, pág. 180). 
muchos poemas gauchescos ${ }^{10}$ sirve para enhebrar el diálogo que quiere desarrollar el autor.

El gaucho José Centurión es enemigo de la guerra y cree con firmeza en una paz duradera. Así puede decir,
1507 ¿Qué se saca con la guerra, don Julián, digameló?,
Ella si sigue, crealó
va a acabar con esta tierra;
desde la mar a la sierra
tuito el páis quiere la paz;
basta de sangre, no más,
alcemos los campamentos, se jueron los sufrimientos, que ya no vuelvan jamás!

Enemigo de la guerra, Centurión creerá que lo mejor es propiciar la fusión partidaria de blancos y colorados, utópica visión del partido único del cual se hablaba en la época.

En el otro extremo, Julián Giménez, predice que no se cumplirán las cláusulas del Tratado de Paz. Habla con amargada experiencia: ha vivido seis años exiliados de su patria, desde el triunfo de la Cruzada del General Flores del Partido Colorado hasta la revolución de 1870. Sostiene que los blancos seguirán siendo perseguidos y humillados en los poblados de la campaña donde las autoridades locales sean del partido triunfante y que la paz firmada es una traición de los políticos ciudadanos. Así se dirá,

$$
\begin{aligned}
& \text { 61 Hoy de nuevo la Nación } \\
& \text { vuelve a cerratnos la puerta } \\
& \text { qué sólo se encontró abierta } \\
& \text { por nuestra revolución; } \\
& \text { otra vez es la ocasión } \\
& \text { de emigrar al extranjero. }
\end{aligned}
$$

Aparentemente no hay más alternativa que

$$
70 \text { ¡dirse... o andar de matrero! }
$$

\footnotetext{
10 La estructura del diálogo gauchesco ha sido esquematizada por Eneida Sansone, analizando la poesía que va de Hidalgo a Lussich. Las etapas formales del mismo serían: saludo, referencias al caballo, invitación a desensillar, se matea, preguntas que dan lugar al desarrollo del tema central, invitación al asado, episodio o episodios secundarios, despedida de los amigos y final donde el autor hace una breve relación de lo dialogado por sus amigos.
} 
En una posición intermedia, el tercer gaucho dialogante, Mauricio Baliente, cree que deben aceptarse por disciplina partidaria las cláusulas del Tratado de Paz, excepto la que habla del desarme.11 Esconder las armas por si las dernás cláusulas no se cumplen y es necesario salir nuevamente a pelear es su consigna y así lo propone casi proféticamente porque en 1875, "el año terrible", el gauchaje oriental estará levantado de nuevo en armas.

Tras el extenso dialogado, un cuarto gaucho aparece en escena. El "matrero" Luciano Santos, alter ego indisimulado del poeta Lussich, ha oído la conversación y será su fiel trasmisor, pero al modo del "mensajero" clásico dirigirái sus palabras a una audiencia compuesta del gobierno, "gefes", "dotores", Ministros, "chupadores" y el propio Presidente de la República, Don Tomás Gomensoro. Luciano Santos pide claramente que no se trate mal al gaucho, que se le permita trabajar, ${ }^{12}$ que se le dé educación ("pongan de balde la escuela/ en vez de comprar tanta arma"), haciendo "su suerte más liviana".

Menos de un año después de publicado Las tres gauchos orientales, en marzo de 1873, Lussich decide "descolgar nuevamente su guitarra" a instancia de algunos amigos y así publica la segunda edición del poema seguida de El matrero Luciano Santos, 4611 versos en su mayoría cuartetas. Ahora los interlocutores son cinco. Los tres gauchos más el propio Luciano Santos y el "rubio" Pichinango hablan y sus opiniones son mucho más uniformes. El paso del tiempo parece haber erosionado las diferencias y haber agotado los apasionados entusiasmos de la post-guerra.

El encuentro de los viejos amigos marca con nitidez ese cansancio.

17 Sabe que se ha güelto viejo, tiene la barba y las motas como esas nubes grandotas, de un blanco medio azulejo"

le dice Baliente a Centurión, pero éste también le observa como

\footnotetext{
11. Las condiciones del pacto firmado suponían, básicamente, la entrega de las armas, una retribución en metálico para los soldados intervinientes, el fin de persecuciones políticas, la entrega de cuatro jefaturas departamentales a los "blancos" y el sometimiento a las nuevas autoridades constituidas.

12 "No lo curtan a macana! al que es paisano de ley,f ni lo traten como a güey/ hincándole la picana;/ su suerte hagan más liviana/ dejen que el pobre trabaje," / recomienda a sus oyentes Luciano Santos en el verso 2316 de Los tres gaucbos orientales. Utilizamos en todos los fragmentos reproducidos el número del verso correspondiente a la edición de Poesía gauchesca prologada y anotada por Jorge Luis Borges y Adolfo Bioy Casares (Fondo de Cultura Económica; México, 1955; 2 vol.)
} 


\section{$22 \mathrm{Y}$ usté ya parece suegro, va doblando el espinazo}

La conversación posterior será estrictamente rememorativa y, a diferencia de Los tres gaucbos orientales, el futuro no tendrá función temática, será el pasado el que adquirirá el tono arcádico de la mítica Edad de Oro de tantos poemas gauchescos, aunque esté jalonado por tristes episodios guerreros que Luciano Santos hilvana. Pero también primará aquí la vocación política circunstancial, por lo cual la posible complejidad temática se adelgazará en aras de una simplificación de carácter e intención didáctica y con muy escasa progresión dramática.

Sin embargo, pese a este propósito limitado en su propio planteo, Los tres gauchos orientales sobresale con nitidez en la vasta producción de la poesía gauchesca uruguaya del período. Con seudónimos de autores más o menos conocidos habían aparecido durante los años posteriores a la paz de abril de 1872 varios libros y folletos con la misma temática -reivindicativa del gaucho.

Una carta en verso, donde Albarao aconseja al paisanaje oriental, es publicada en 1872 con el título significativo de $E l$ gaucho oriental ("Colección de poesías compuestas por el paisano Sinforiano Albarao contestando al gaucho Calisto Juentes"). La carta insiste sobre la inutilidad de las guerras civiles y en décimas poco imaginativas comenta el acuerdo de paz firmado. Más pobremente poética es la obra de Julio Figueroa, escudado bajo el seudónimo de Calisto Juentes, aunque la especulación temática sea más ambiciosa: el gaucho enfrentado a los políticos va a desaparecer marginado por las condiciones sociales instauradas por la paz.

Otros poemas con seudónimo aparecen en el mismo periodo. "Calisto el Nato" (Alcides de María) dirige en Preludio de dos guitarras (1876) cartas versificadas a un interlocutor, Joaquín Rodajas, sobre la vida pa. sada en un campamento del ejército al que fue llevado por la fuerza. No faltan humor y gracia en estos "cuadros de la guerra y de la paz". Tal como "Anastacio el Pollo" fuera el exitoso seudónimo de Estanislao del Campo en 1859, en ocasión de publicarse el popular Fausto, en 1873 aparece "Aniceto Gallareta" escondiendo la no menos popular pluma de Isidoro de María. ${ }^{13}$

No falta la defensa del "gaucho colorado" en este conjunto de fo-

13 En La imagen en la poesia gauchesca (Facultad de Humanidades y Ciencias; Montevideo, 1962), Eneida Sansone incluye un interesante Diccionatio de Seudónimos de poetas gauchescos. Allí se descubre que Lussich utilizó los seudónimos de Luciano Santos, Paulino Lucero y el gaucho Luciano Santos en alguna de sus poesías sueltas. 
lletos y así "Calixto Rojas" lanza romances donde destaca el valor del Colorado en las patriadas, para concluir reclamando que sean mejoradas las condiciones sociales en que viven los gauchos de ese partido. El mismo tema de la Revolución del Coronel Aparicio y la vida del gaucho "blanco" o "colorado" es tomado por la ficción ${ }^{14}$ y formará parte de una creciente tradición plasmada en el folklore popular (canciones, payadas, décimas de venta callejera, etc...) hasta su agotamiento imaginativo a principios del siglo $\mathrm{Xx}$.

Ahora bien, esta común voluntad de fidelidad analítica y preservación casi historicista del "gaucho que desaparece", en tanto parte en el poema de Lussich de una realidad "externa" ya delimitada, contribuye a independizar y a autonomizar estéticamente a la obra como totalidad. El confinamiento progresivo a la "reservación" social y estética del gaucho como prototipo revolucionario, permite - casi paradojalmente- una lectura independiente, "autónoma", y otorga una cierta funcionalidad literaria sin direcciones diversificadas, ni aperturas tangenciales de reconocimiento "actualizado" a la estructura total del poema.

Sin embargo, hay un segundo nivel en el estudio de Los tres gauchos orientales de indudable importancia $y$, nos atreveríamos a decir, de mayor significación actual: el lenguaje poético asumido como forma expresiva de un lenguaje "hablado", correlato y trasposición poética que vale la pena analizar con mayor detalle.

\section{LENGUAJE hablado Y TRASPOSICIÓN POÉtica}

El lenguaje adoptado por Lussich en Los tres gauchos orientales supone un importante esfuerzo de aproximación a las bases reales de una lengua hablada, sin mayor tradición previa (Hidalgo, Ascasubi), pero en la cual querían descubrirse y fijarse las notas totalizadoras de la condición gaucha. Lo gauchesco se quiere entender como posición total de la psique, como toma de una realidad y su versión por el lenguaje, esa cualidad étnica con cariz geográfico y temporal que Ezequiel Martínez Estrada reclamaba como nota distintiva de esta literatura:15 la "vida

14. En Campo de Javier de Viana hay relatos escenificados en la revolución de 1870. Algunas de "las relaciones de oposición" que analizamos en función de Los tres gauchos orientales aparecen en esa obra, luego en Leña seca donde ya indignado por "el criollismo falso" habla de "los tiempos bárbaros y avergonzadores del caudillismo analfaberto y sensual", aunque en Con divisa blanca se refiera a "los políticos de gabinete, los que nunca han entrado en el alma del pueblo y pontifican desde el altar de su ilustración libresca."

15 En Muerte y transfiguración de Martin Fierro, Ezequiel Martínez Estrada dedica un largo capítulo a "El habla del paisano" (Fondo de Cultura Económica; 2a. edición. Bs. As., 1958; Tomo I, p. 227 a 276) donde estas ideas se desarrollan en profundidad, especialmente en el sub-capítulo "La lengua oral" (pág. 239). 
entera" del gaucho en la cual el lenguaje es función expresiva y modal fundamental.

El idioma "hablado" y cotidiano accede, con sus giros populares, a una poesía que hasta ese momento había utilizado en su expresión literaria una formulación lingüística ineo-clásica española o había intentado articular una literatura "nacional" sin bases idiomáticas reales. La retórica neo-clásica es abandonada por la poesía gauchesca para lanzarse a cantar en el verso común de la poesía tradicional española que, como ha señalado Lauro Ayestarán, "corre con la fluidez de la palabra cotidiana, pero con la gracia del canto". ${ }^{18}$

La lengua como material primario, "el estilo especial que usan nuestros hombres de campo", como dijera el propio Lussich, tiende a "cristalizarse" y a estructurarse poéticamente en términos lingüisticos paralelos a la realidad abordada. Los tres gauchos orientales no sólo quiere trasmitir una problemática política, sino que aspira a organizar un "modo" verbalizado de entenderla. Al optar por un lenguaje estál eligiendo una actitud que quiere ser capaz de abarcar en su totalidad los modos de sentir y reaccionar de los gauchos "reales".

Ascasubi se había planteado similares propósitos. "Teniendo en vista ilustrar a nuestros habitantes de la campaña las más graves cuestiones sociales que se debatían en ambas riberas del Plata - escribe_-17 me he valido en mis escritos de su propio idioma y sus modismos para llamar la atención, de un modo que facilitara entre ellos la propagación de aquellos principios."

Aunque la comparación de Leopoldo Lugones entre el nuevo lenguaje de la Divina Comedia y el instaurado por el Martín Fierro parezca exagerada, ${ }^{18}$ es evidente que el lenguaje de la literatura gauchesca es un lenguaje de nueva formación, con un concepto de vida integral y riqueza recién descubierta que impiden que un poema como Los tres gatuchos orientales se acartone o se estructure con rigidez en su mismo origen. En esta misma medida se explica parte del éxito que acompañó sus primeras ediciones ${ }^{19}$ y la cómoda inserción del poema en la que es hoy una tradición literaria indiscutida.

16 Ayestarán, Lauro. La primitiva poesía gaucbesca en el Uruguay (El Siglo Ilustrado; Montevideo, 1950).

17 De "Al lector" en Santos Vega payador (París, 1872).

18 De "Martín Fietro es un poema épico", por Leopoldo Lugones, incluido en Martin Fierro (Cuadetnos de Marcha No. 66; Montevideo, octubre 1972). Esta publicación no cita la fuente de donde ha sido extraído el trabajo de Lugones. Sin embargo, es posible reconocer fragmentos de la serie de conferencias pronunciadas por Lugones en el Teatro Odeón de Buenos Aires en 1913 y luego recogidas en el libro El payador.

10 Ningún libro editado en el Río de la Plata había alcanzado hasta ese momento un tiraje tan alto. 
Sin embargo, es notoria una tensión permanente con efectos de presión deformadora entre los diferentes niveles de la lengua manejada por Lussich como presunta "habla del gaucho". Al intentar expresar sentimientos e ideas que responden a una información y a una cultura cuyo modo de expresión pertenece a otra "forma de hablar", Lussich no puede evitar caer en lo que Martínez Estrada llamó "la extranjería de lo psíquico", sufriendo las palabras una cierta violencia interior no siempre resuelta. Evidentemente, el "habla" es valor esencial del poema, pero no siempre traduce la proyectada preocupación de preservación lingüística del autor.

De cualquier modo, Lussich supera el esquema de que para crear una literatura - aquella "naturalización de los símbolos" de que hablábamos al principio- bastan solamente los argumentos, ambientes y personajes "nacionales" e intuye que hay que intentar el traslado del lenguaje real, la forma de expresión con todos los giros y modismos que puedan ser indicativos de una psicología y una estructuración determinada de la realidad en el plano literario.

El sentido coloquial, con exagerados modismos locales, cierta amplitud de la oración o metáforas con vulgarismos, subyacen en todo el poema, siendo evidente que Lussich quiere conservar el "pathos" oral de que hablaba Nietzsche como una forma legítima de autenticidad. Es deliberado su propósito por dar mayor consistencia y veracidad a la obra: la verdad es lo verbal y el valor de esta verdad es independiente de los hechos contados, ya que está en la forma verbal de contarla.

En esta forma verbal hay cierta tendencia a la inferiorización $y$ empobrecimiento del lenguaje, a fuer de ser realista. Ya decía el recordado Martínez Estrada que "el habla gauchesca es reducídisima porque ha eliminado más que innovado" poéticas" y propensiones "a filosofar", constriñe también su vocabulatio.

Sin embargo, bajo este lenguaje tosco, desaliñado, con un vocabulario muchas veces forzado para dar una falsa idea de "gauchismo", halagando el posible gusto popular del lector, Lussich maneja con habilidad la fórmula métrica de la poesía gauchesca tradicional. $\mathbb{E l}$ verso octosilábico con dos formas estróficas -el romance fragmentado en cuartetas y la décima que a veces forma un "trovo"21_- es tomado sin variantes por Lussich. Los 23.76 versos que componen la versión definitiva de Los'tres

20 O.C., pág. 272.

21 Entendemos el "trovo" como una décima encabezada por una cuarteta cuyos versos se reproducen, por su orden, en los últimos versos de las cuatro décimas que componen el poema. Repitiendo ordenadamente estos cuatro últimos versos se reproduce la cuarteta inicial o "cabeza". Esta fórmula folklórica corresponde a la "glosa" del cancionero hispánico. 
gauchos orientales se agrupan así en 247 cuartetas, 135 décimas y 38 versos romanceados de lenguaje inspirado y de gran naturalidad en la elocución, como ha precisado Eneida Sansone, aunque puntualice, al mismo tiempo, que gran parte del estudio que el lenguaje de Iussich merece en su expresión y versificación poética, sigue lamentablemente inédito. ${ }^{22}$

\section{EL DIÁLOGO COMO MODO DRAMÁTICO DE LA EXPRESIÓN}

El "diálogo", que ya había permitido a Bartolomé Hidalgo una exitosa fórmula poética en su Diálogo entre Cbano y Contreras, ${ }^{23}$ reaparece como modo de expresión en Antonio Lussich. La clásica "relación", el "cielo", habían sido la forma original utilizada por Hidalgo, luego abierta al diálogo y rápidamente difundida en la poesía gauchesca posterior por Ascasubi, Araucho, Luis Pérez, Godoy y varios de los poetas anónimos del período.

Pero aún en los poetas mayores, como Ascasubi en Paulino Lucero, ${ }^{24}$ el diálogo carece de efectividad dramática: Jacinto informa, Simón escucha y a todo lo más ratifica, pregunta o incita a su compañero a proseguir su narración. El diálogo es unilateral y carece de toda controversia.

La influencia de este modo expresivo en Lussich es notoria, especialmente en el acento patriótico y humano que aparece en los tres gauchos dialogantes, embargados de nacionalismo como los de Hidalgo lo estaban de sentimiento independentista y americano. Como ha señalado Juan Carlos Guarnieri25 la "deuda" con el canto de "la Patria Vieja" aparece ya en el subtítulo de Los tres gaucbos orientales - "Diálogo

22 En su completa introducción a la obra de Lussich, Eneida Sansone (O.C., p. XXXII) escribe: "El uso de aumentativos y diminutivos, superlativos y gerundios de pura cepa gaucha, a veces sin correspondencia castellana alguna; la abundancia de perífrasis y disfemismos; el uso del paréntesis y los puntos suspensivos, el empleo del solecismo y de toda suertel de fórmulas lexicales originales para dar idea de ubicación o procedencia, tiempo, cantidad, tamaño y espacio, junto con otros elementos no ya propios de la lengua sino del estilo, como son, por ejemplo, las imágenes de todo tipo, hacen de los poemas de Lussich documentos cuyo valor todavía resta descubrir."

23. "Diálogo patriótico interesante" y "Nuevo diálogo patriótico incluido en Poesia gauchesca (O.C., pág. 7 y pág. 17).

24 En Paulino Lucero (Obras completas, París, 1872) dialogan Jacinto Amores y Simón Peñalva, junto a la otilla del Queguay, sobre las fiestas civicas celebradas en ocasión del aniversario de la jura de la Constitución, efectuadas en Montevideo en julio de 1833.

25 "En el centenario de "Los tres gauchos orientales" incluida como introducción en la edición de Los tres ganchos orientales de la colección Vaconmigo de la Biblioteca Marcha; Montevideo, 1972. 
entre los paisanos Julián Giménez, Mauricio Baliente y José Centurión" que evoca los títulos de Hidalgo. ${ }^{26}$

Sin embargo esta forma "canónica" del poema gauchesco como fuera bautizada sin ironía, es potenciada a otra dimensión dramática por Lussich al llevarse a tres, cuatro y cinco los dialogantes de sus obras y al confrontarse en el diálogo opiniones diferentes. La fórmula primitiva "unipersonal", pautada por breves acotaciones e interrogantes, es sustituida por un auténtico diálogo teatralizado donde cada interlocutor juega su papel. Esta escenificación poética ha sido considerada por Jorge B. Rivera como "una forma que resume intencionalmente mayor número de requisitos gauchescos"27 y ha sido enfatizada por Jorge Luis Borges como el elemento de mayor valor en el poema de Lussich. Dice el autor de Discusion: "Entre amargo y amargo, tres veteranos cuentan las patriadas que hicieron. El procedimiento es el habitual, pero los hombres de Lussich no se ciñen a la noticia histórica y abundan en pasajes autobiográficos. Estas frecuentes disgresiones de orden personal y patético, ignoradas por Hidalgo y por Ascasubi, son las que prefiguran el Martín Fierro, ya en la entonación, ya en los hechos, ya en las mismas palabras. ${ }^{28}$

Este diálogo múltiple, a varias puntas, enriquece la base del poema de Lussich, ya que aunque se haya propuesto una línea central de raíz política, la obra -a través del diálogo- va creando otros focos de interés. Ello nos lleva, inevitablemente, a la segunda parte de este trabajo: la operación por la cual los distintos valores que estructuran internamente el poema son analizados.

\section{II: LAS CATEGORÍAS INTERNAS DEL POEMA}

La operación de análisis de Los tres gaucbos orientales, que empezara con la identificación y actualización de los valores de los elementos representativos "externos", incluído el lenguaje, tiene su continuación en una segunda operación: aquella que establece el total de las relaciones entre los valores y elementos que entran en juego en el poema y en la actualización de dichas relaciones como "parejas contradictorias" y dialécticas.

Esta segunda operación supone la formación de relaciones "internas" en la obra de Lussich sobre la base de un doble principio: la variedad

26 "Diálogo patriótico interesante entre Jacinto Chano, capataz de una estancia en las islas del Tordillo, y el gaucho de la Guardia del Monte". (Hidalgo; Poesía gaucbesca, T. I, pág. 7).

${ }_{27}$ Rivera, Jorge B. La primitiva literatura gauchesca (Jorge Alvarez; Buenos Aires, 1968; pág. 44).

28 Discusión (O.C., pág. 25). 
dentro de la unidad. Esta fórmula general y simple regula no sólo la formación de las partes menores y la estructura total de Los tres gauchos orientales sino de cualquier poema que of rezca un mínimo de complejidad.

Del principio de variedad - siguiendo nuevamente en esta materia a Juan Ferraté y la tradición crítica que él recoge ${ }^{20}$ - se desprenden algunas consecuencias:

1 - las relaciones entre los elementos del poema no son telaciones simples, sino complejas, aunque aparezcan muy claras (hasta ingenuamente simplificadas) en función de la percepción total de las relaciones de la obra.

2 - básicamente esas relaciones no son de concordancia y afinidad, sino relaciones de oposición, disonancia o disconformidad. Los valores puestos en juego no necesitan ser de una misma categoría, sino que son de categorías heterogéneas.

Por su parte, del principio de amidad se deriva el hecho de que cuanto mayor sea el número de relaciones que entren en juego, tanto más necesario resulta que esas relaciones se establezcan entre un número limitado de elementos, ya que de otro modo, la unidad de la obra correría peligro de cuartearse en grupos diferentes de elementos relacionados entre sí, pero sin que guarden relaciones un grupo con otro.

\section{Las Relaciones de Oposición}

Una misma identidad gauchesca reivindicada en Los tres gauchos orientales, no impide que, en la propia estructura del poema, se den los antagonismos de valores en forma de "parejas contradictorias". A través de estas relaciones por oposición el autor ha querido resaltar las contradicciones "externas" que derivaron, a su juicio, de la paz firmada unos meses antes de la redacción final de su obra.

En estas "parejas" de valores opuestos se repiten muchos de los temas que son "leit-motiv", no sólo de la literatura gauchesca, sino de parte de la universal. Por ejemplo, las contradicciones entre la guerra y la paz, la evocación de una Edad de Oro pasada, los regresos a la patria, a la tierra y al hogar, muchas veces destruido, la juventud y la vejez y la utilización del héroe por parte de quienes tienen otros fines, abandonándolo luego a una suerte 'desgraciada. La lista podría ser ampliada en extensión y profundidad, pero aquí sólo nos interesa destacar los tipos de relación antagónica que surgen con mayor nitidez de la obra de Lussich; a saber,

29 Especialmente I. A. Richards ("Poetic Process and Literary Analysis", en Style in Langtuage, Cambridge, Mass. 1960). 


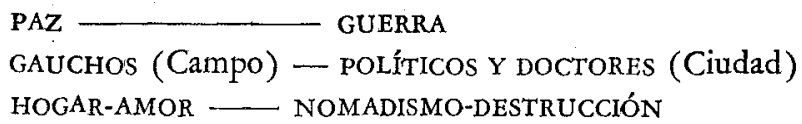

\section{Functón aglutinante de La guerra}

Cuando los tres gauchos orientales o los cinco de El matrero Luciano Santos recapitulan un pasado dinámico, lo hacen desde un presente "congelado", inmovilizado por la Paz de Abril. Con ello se establece una clara línea divisoria entre períodos que se aparecen como esencialmente antagónicos: la guerra que permitía la acción y la paz que disuelve al grupo de compañeros.

Esta inmovilidad y esta división llevan a que el autor asuma un punto de vista histórico: se están recapitulando acontecimientos sin "continuidad" en el presente, por lo cual se quiere fijar una realidad que ya no existe, llamando la atención sobre un mundo que está en una especie de "reservación". La relación está bloqueada por los términos de un silogismo muy simple: esta Paz que todos festejan es la que ha levantado un muro divisorio "aislando" al gaucho; la Paz lo encierra porque en las condiciones firmadas no hay lugar para él. Si en la guerra el gaucho puede ser soldado y héroe, aflorando sus condiciones natas de bravura, particular sentido de la libertad e independencia, estas son virtudes automáticamente peligrosas y temidos ingredientes de la paz. Aunque lo sugiera el gaucho Centurión, no es posible sustituir el fusil por el arado. ${ }^{30}$

En este sentido, Los tres gauchos orientales se convierte en espléndido documento testimonial de una teoría de base paradojal: la guerra es el vínculo de unión, la forma de aglutinamiento y creación de valores nacionales en los pueblos gauchos desperdigados en la campaña. El vagar nómada es virtud ${ }^{31} \mathrm{y}$ las formas de hogar, familia estable, ceden su lugar a la sociedad de guerra. Mundo sin "hogares-templo", la guerra permite la formulación y consolidación de los sentimientos supra-individuales que caracterizan el sistema de valores gaucho: fraternidad, amistad, lealtad a hombres y banderías, coraje y todos los conceptos que justifican el nomadismo y lo mitifican al punto de que el desprendimiento de pertenencias y el abandono de propiedades pueden ser virtudes. La facilidad para romper con el vínculo nativo, ensillando un caballo con lo esencial, aparece varias veces reiterada en Los tres gauchos orientales.

30 Verso 1753: "a esta patria desdichada/ y en vez de empuñar la lanza/ darle al arao con pujanza/ y a toda tarea honrada."

31 En $E l$ matrero Luciano Santos se mitifica la condición vagabunda del gaucho, especialmente a través del relato que de su propia vida hace luciano Santos. 
Basta ver cómo las únicas circunstancias donde hay agrupamientos humanos son las conjuradas por el clarín guerrero:

Y cómo estaba Aparicio

la gente caiba a granel;

viera qué enjambre o tropel!

creí que juera el día del juicio!

El caudillo aglutina, la guerra une y no es difícil concitar el entusiasmo popular cuando los soldados gauchos entran en los pueblos,

1531

Viera el gentío ese día

de alborotao cómo andaba

cada cual se disputaba

al recibir los milicos,

viejas, mozas, pobres, ricos,

tuito el mundo se ofertaba.

Había bulla y contento, campaneo atronador,

no se oía del dolor

la amargura ni el tormento.

No hay escena de paz que reúna en Los tres gauchos orientales notas de mayor entusiasmo y felicidad que esta instancia de la guerra: en acción revolucionaria los gauchos están contentos y no hay lugar para el dolor. Es con la paz que llegan sus males. Por lo pronto, la dispersión de los compañeros y amigos que, como los tres gauchos, están reunidos para despedirse. Ha dicho Julián,

$$
\begin{aligned}
& \text { A visitarlo venia } \\
& \text { pues nos piensan licenciar, } \\
& \text { y no me quiero largar } \\
& \text { sin que hablemos este día. }
\end{aligned}
$$

Pero además, todos sospechan que la autoridad emergente de la paz los habrán de marginar de los nuevos "centros" aglutinantes que se habrán de formar: de las pulperías, de las carreras donde gritarán "ese enemigo! es blanco, salga pa juera!", de la banca, de los bailes donde "le quitan la consentida" y hasta del propio pago donde le dirán "gaucho vago".

Frente a esta paz de condiciones temibles, no es extraño que los gauchos se pregunten, 
1803

- ¿Cómo podremos vivir

trataos de un modo tan cruel?-

Lo único que puede gritarse es

guerra y guerra sin cuartel!

Hasta vencer o morir!

\section{LA OPOSICIÓN DE LA LANZA Y DE LA PLUMA}

La paz es traición porque ha sido hecha por políticos y doctores ciudadanos ajenos al mundo tural del gaucho. Este simple silogismo está basado en una lógica desconfianza frente a las condiciones de una paz elaborada lejos de quienes protagonizaron y llevaron adelante la revolución. Los sofisticados razonamientos urbanos de los políticos escapan al pensamiento esquematizado del gaucho y surge así en el seno: del poema una nueva relación antagónica basada en dualismos, como el de civilización-barbarie, de larga data americana..$^{32}$

Así, los calificativos son duros:

307

Pero pa más estropicio

los letraos se nos volvieron, y ya también disunieron

a Muniz con Aparicio allí empezaton su oficio de intrigas y plumería, ansí que de día en día la cosa tan se frunció, que el patriotismo voló pues sólo ambición había!

Si Baliente, de natural ecléctico, habla así, no puede extrañar que Julián sostenga

$Y$ a la oreja siempre andan

y como sarna se pegan;

32 De la obra de Sarmiento, Facundo, publicada en 1845, hasta la fecha de la edición de Los tres gauchos orientales el debate sobre este dualismo antagónico de la concepción americana se extiende con interesantes variantes como la polémica periodística entre Bernardo P. Berro y Manuel Herrera y Obes en la prensa uruguaya del Cerrito y la Defensa. 


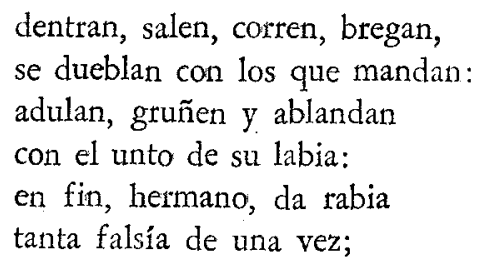

En este esquema simplificado el militar aparece como aliado de los intereses del gaucho. No los traiciona como los políticos.

401

$$
\begin{aligned}
& \text { No es el general, cramé, } \\
& \text { quién nos ha clavao del pico; } \\
& \text { son los que untan el bolsico } \\
& \text { con la sangre de este páis; } \\
& \text { que el diablo les diera máiz! } \\
& \text { en vez de pluma y tintero. }
\end{aligned}
$$

A los ojos del gaucho,

$$
\begin{aligned}
& \text { hubiera sido otra cosa } \\
& \text { sin los enriedos y prosa } \\
& \text { que nos trujo tal gente, } \\
& \text { que se llama inteligente } \\
& \text { y nos quiere embozalar. }
\end{aligned}
$$

A la hora de la paga por los servicios prestados como soldados de la revolución, los tres gauchos sospechan que "entre velas y candiles se irán los quinientos miles, y pa el gaucho... no habrá un queso". Nuevamente se categoriza al político ciudadano como hablador ("quizás muevan la sin güeso pa darnos algún consuelo"), pero el razonamiento abre la compuerta a cierto resentimiento y a la comprobación tardía de haber sido utilizado y luego abandonado por los líderes.

$$
\begin{aligned}
& \text { Sólo cuando nos precisan } \\
& \text { entonces sí, son cumplidos, } \\
& \text { peto dispués de servidos } \\
& \text { si nos encuentran nos pisan; } \\
& \text { y si acaso nos devisan } \\
& \text { se soslayan del camino, } \\
& \text { por qué un tinterillo fino } \\
& \text { con un gaucho se deshonra; }
\end{aligned}
$$




\section{EL AMOR AUSENTE}

La carencia de hogar, entendido como templo familiar, o su vulnerabilidad extrema se repite como constante en Los tres gauchos orientales, sin que aparezcan variantes al "motivo" tradicional de la poesía gauchesca: la revolución y la guerra es más importante que cualquier querencia estable. Así Baliente recierda sin mucha nostalgia como,

105

yo tuve ovejas y hacienda

caballos, casa y manguera;

mi dicha era verdadera...

Sin embargo, pese a que "feliz vivía como un rey" el llamado de la guerra no le permite dudar y así confiesa

$$
\begin{aligned}
& \text { pero el clarín con su voz } \\
& \text { tuito abandonar me hizo; } \\
& \text { saqué a gatas lo preciso, } \\
& \text { y a lo demás, dije adiós! }
\end{aligned}
$$

Tradicionalmente la literatura gauchesca no ha dado mucha importancia al hogar, ni como recinto material, ni como centro de cohesión familiar, ${ }^{33}$ reflejando siempre impresiones de inestabilidad, desamparo y renunciando a todo atisbo de paz y sosiego, tal como puede dar la más humilde casa de otras literaturas.

Como Baliente, el gaucho Centurión también ha abandonado todo cuando lo han buscado para enrolarse en la revolución. Lo imprescindible lo carga en su caballo, convirtiéndose el recado en una suerte de "espacio concentrado" del hogar abandenado. Allí lleva todo cuanto necesita: manta, poncho, cojinillo y una pequeña" maleta con "dos mudas de ropa nueva". El hogar que ha quedado atrás no importa: "mi cueva" puede ser librada a los "caranchos" o destruida como sospecha el mismo Baliente,

116

$$
\begin{aligned}
& \text { Carchas, majadas y querencia } \\
& \text { volaron con la patriada, } \\
& \text { y hasta una vieja enramada } \\
& \text { que cayó... . supe en mi ausencia. } \\
& \text { La guerra se lo comió }
\end{aligned}
$$

33 Martínez Estrada, O.C., pág. 381. 
y el rastro de lo que jué

será lo que encontraré

cuando al pago caiga yo!

Lo que sospecha Baliente en Los tres gaucbos orientales es ya una certeza un año después en El matrero Luciano Santos, cuando Luciano Santos cuenta cómo

2195

$$
\begin{aligned}
& \text { Sali pa el pago rumbiando } \\
& \text { al ser un hecho la paz; } \\
& \text { mi deseo era tan veraz } \\
& \text { que en la marcha iba volando; } \\
& \text { más vide al llegar, temblando, } \\
& \text { que de tanto que dejé, } \\
& \text { ya nada quedaba en pie } \\
& \text { sino una triste tapera! }
\end{aligned}
$$

En este mundo no hay amor, aunque Centurión se diga

753

$$
\begin{aligned}
& \text { Es el amor que alimenta } \\
& \text { el árbol de la esperanza; } \\
& \text { feliz aquel que lo alcanza } \\
& \text { y en el alma lo sustenta }
\end{aligned}
$$

El orden de relaciones creado por la guerra es excluyente de toda idea de amor, ya

$$
\begin{aligned}
& \text { que aunque el amor y la guerra } \\
& \text { son cuasi de un parecer; } \\
& \text { nos yere el uno sin ver, } \\
& \text { nos echa la otra por tierra. }
\end{aligned}
$$

El gaucho Julián responde, por su parte, casi con brutalidad a toda posible idea del amor.

ya que, 
Yo no entiendo otros amores

que resporar los olores

di un güien frasco de giñebra.

Recordaba Martínez Estrada" que en "la pintura del amor nuestros poetas gauchescos fueron groseramente ineptos, y recurrieron infaliblemente a fórmulas estereotipadas de insolente vacuidad", por lo cual el vocabulario aparece reducido y sin vivencias para lo que puede ser pasión. La guerra esfumina la figura de la mujer, careciendo de consistencia como personajes, a todo lo más apareciendo como contrapunto de la soledad actual del personaje.

El gaucho difícilmente se confiesa enamorado, ya que hacer alabanza de una mujer es sinónimo de debilidad y motivo de chiste, burla de amigo. El amor parece disminuir atros valores estrictamente viriles de la sociedad guerrera. Julián lo puntualiza con claridad en El matrero Luciano Santos,

Los cuatro, aunque medio blandos, en chicas no nos paramos; si en nuestro paso encontramos quien nos quiera armar un frito pa el otro mundo lo echamos, si rezarle ni un bendito.

Mejor pelear que amar, aunque Luciano recuerda a una mujer que quiso "como amor primero" y culpe a la guerra de que la haya "marchitado como a una violeta".

También recuerda Centurión a "la prenda que me ha robao el sosiego" a la que califica de "tirana", pero a la que abandonó el mismo día que la había conocido. Pero la inconstancia se atribuye sin dudas a la mujer. Así es a la mujer a quién se dedican los mayores reproches de cualquier cambio de sentimientos.
La mujer suele cambiar como el tiempo y los asuntos. . y el que viene atrás arréa los bienes de los difuntos.

34 Idem, pág. 394. 
La carencia de hogar y de amor, sin embargo, no es reciente. Los gauchos que ahora piensan así es porque han crecido con esa escala de valores que aprendieron, muchas veces duramente, en su propia infancia. Luciano Santos no sabe ni en qué año nació, "ni del vientre que salió". La ruptura ha sido brutal:

3615

Mis padres, lejos de sí

como cachorro apestao,

me echaron abandonao

cuando entuavía mamaba.

Una vida nómade, sin hogar, lo lleva a considerar que

4249

y ese andar de lao a lao

sin familia y sin querencia,

llorando del bien la ausencia,

mucho. . . mucho me ha enseñao!

Todas estas parejas de valores antagónicos -a las que poidrían añadirse otras - van estructurando un poema de particular valor concentrado, donde es evidente que el esfuerzo de conversión y "naturalización de símbolos" a la literatura gauchesca se da con nitidez en una obra de rara virtud "unitaria". En este sentido entendemos a Los tres gauchos orientales como una obra importante, aunque muchos de sus versos hayan pagado un fuerte tributo a su circunstancialidad política.

Sin embargo, pese a esta dependencia reconocida por el propio autor, no puede dejar de tenerse en cuenta que la concentración unitaria de valores opuestos del mundo gauchesco desaparecido ha permitido que sea posible hoy una lectura total y autónoma de la obra de Lussich sin otra apoyatura que su propio universo y lenguaje poético. $Y$ éstas son raras virtudes que otros poetas, menos comprometidos aún con su tiempo, no pueden reivindicar hoy con tanta legitimidad como lo hizo en 1872 el juvenil y apasionado autor de Los tres gauchos orientales.

FERNANDO AINSA

Montevideo (Uruguay) 


\section{BIBLIOGRAFIA}

1. Obras de antonio D. Lussich:

A) OBRAS GAUCHESCAS

_. Los tres gauchos orientales: (Imp. "La tribuna"; Buenos Aires, 1872; 59 págs. 1a. edición).

- Los tres gaucbos orientales seguido de El matrero Luciano Santos (Imp. del Comercio; Buenos Aires, 1873; 2a. edición).

-. Los tres gauchos orientales; El matrero Luciano Santos; El inválido Oriental (Imp. La Democracia; Montevideo, 1877; 3a. edición).

- Los tres gauchos orientales y El matrero Luciano Santos, seguido de Cantalicio Quirós y Miterio Castro en un baile del Club Uruguay.

(Barreito y Ramos; Montevideo, 1883; 365 págs.; 4a. edición).

- Los tres gauchos orientales y otras poesiats. Edición prologada por el Dr. Mario Falcao Espalter. (Claudio García; Montevideo, 1919, 419 págs.).

- Los tres gauchos orientales. Colección de Clásicos Uruguayos; Vol. 56; Prólogo de Eneida Sansone de Martínez; Biblioteca Artigas del Ministerio de Instrucción Pública; Montevideo, 1964; 350 págs.).

-. Los tres gaucbos orientales. Colección Vaconmigo; prólogo y notas de Juan Carlos Guarnieri; introducción de Angel Rama; Biblioteca de Marcha; Montevideo, 1972; 168 págs.).

\section{B) Otras obras de LUSSICH}

- El naufragio de la barca inglesa Mabel. (EI Telégrafo Marítimo; Montevideo, 1886; 36 págs.).

- Naufragios célebres en el Cabo Polonio, el Banco Inglés y el Océano Atlántico. (El Siglo Ilustrado; Montevideo, 1893; 242 págs.). Hay una edición posterior de 1938 (Claudio García; Montevideo) y una traducción al inglés, impresa en Montevideo en 1894 (El siglo ilustrado; traducción de Henry C. Ayre).

C) Obras de Lussich incluídas en ANTologías

Araujo, Orestes. Cuadros descriptivos del Uruguay por sutores macionales y extranjeros. (Dornaleche y Reyes; Montevideo, 1895; 318 págs.).

Borges, Jorge Luis y Bioy Casares, Adolfo. Poesía gauchesca. [El tomo segundo incluye la obra gauchesca completa de Lussich ]; Fondo de Cultura Económica; México, 1955; 1a. edic. 2 vols.). 
Caillet Bois, Julio. Antología de la poesía bispanoamericana, Aguilar, S. A.; Madrid, 1958; 1987 págs.).

Casal, Julio. Exposición de la poesia uruguaya, desde sus origenes basta 1940. (Editorial Claridad; Montevideo, 1940; 766 págs.).

Chávez, Fermín. Poesía rioplatense en estilo gaucbo. (Ediciones Culturales Argentinas; Buenos Aires, 1962; 155 págs.).

García, Serafín J. Diez poetas gauchescos del Uruguay (Blundi; Montevideo, 1963; 121 págs.).

García, Serafín J. Panorama de la poesía gauchesca y nativista del Uruguay. (Editorial Claridad; Montevideo, 1941; 311 págs.).

Guarnieri, Juan C. Versos gaucbescos y nativistas. (Editorial Ombú; Montevideo, 1949; 129 págs.).

Magariños Cervantes, Alejandro. Páginas uruguayas. Album de poesías (Tomo I. Imp. La Tribuna; Montevideo, 1878).

Sansone, Eneida. La poesia gauchesca. Cedal, Buenos Aires, 1968; 116 págs.

\section{CRÍtica SOBRE Lussich (Selección)}

Alvarez, José Carlos. Una voz rescaiada del pasado. (Diario La Mañana, Montevideo, 19 de febrero de 1965).

Borges, Jorge Luis. Discusión. (Emecé, Buenos Aires, 1964; 3a. edición).

Caillava, Domingo A. Historia de la literatura gauchesca en el Uruguay, 1810-1940); (Claudio García, Montevideo, 1945). Referencias a Lussich en páginas 46, 55 y 196.

Martínez Estrada, Ezequiel. Muerte y transfiguración de Martin Fierro. (Fondo de Cultura Económica; Buenos Aires, 1958; 2a. edición, 2 vols.).

Contiene varias referencias a la obra de Lussich en relación a la de Hernández.

Sansone, Eneida. La imagen en la poesia gauchesca. (Facultad de Humanidades y Ciencias; Montevideo, 1962; 422 págs.). 